\title{
Active damping of multidimensional mechanic systems
}

\author{
Zdeněk Úředníček ${ }^{1, *}$, and Jaroslav Maloch ${ }^{2}$ \\ ${ }^{1}$ Department of Automation and Control, Tomas Bata University in Zlin, Jižní Svahy, Nad Stráněmi 4511, 760 05, Zlin, \\ Czech Republic \\ ${ }^{2}$ Department of Production Engineering, Tomas Bata University in Zlin, Vavrečkova 275,760 01 Zlin, Czech Republic
}

\begin{abstract}
At many motion control tasks, the problem of oscillations existence in multidimensional system with limited motion control and imperfect or complicated state quantities measurement possibility exists. Paper describes active damping simple possibility of these type systems and by two-dimensional system physical model shows active damping possibility also with indirect state quantities measurement option.
\end{abstract}

\section{Introduction}

This paper goal is to introduce some pieces of knowledge relevant to active damping of mechanical systems with more degree of freedom with limited action interventions' possibilities and limited or complicated quantities measurement possibility. This problem often occurs at different mechanical systems motion control types serving as optical (surveillance) or other systems porter, which depend on effector systems positional state accuracy, and when actuators functions in some generalized coordinates only.

As such system example can be cameras porter, laser scanning system porter created from no ideally stiff bodies, weapons porter system with uncontrolled projectiles, but also manipulator with no ideally stiff arms for exact assembly application, not to mention, for invasive medicine application.

\section{Description of system with one degree of freedom and its active damping principle}

For linear system from Fig.1, where force $f(t)$ is created by actuator according to Fig.2 reads:

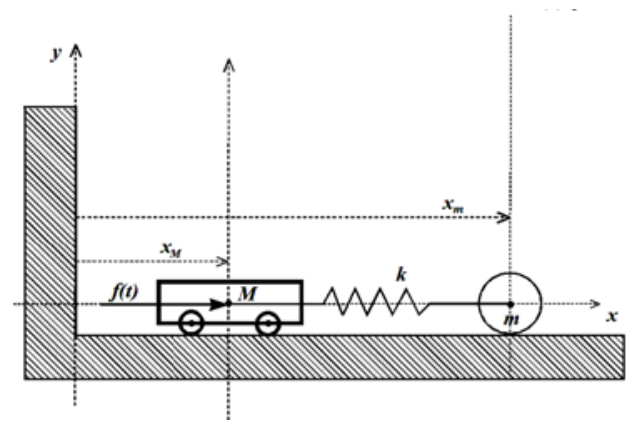

Fig. 1. Active damping principle of system with one degree of freedom.

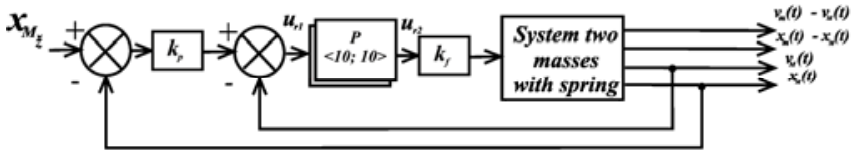

Fig. 2. Masse M cascade position control.

$$
\begin{aligned}
& f(t)=k_{f} \cdot\left\{k_{p v} \cdot[\overbrace{k_{p} \cdot\left(x_{M z}-x_{M}\right)}^{u_{r 1}}-1 / 200 \cdot v_{M}]\right\}= \\
& =k_{f} \cdot k_{p v} \cdot k_{p} \cdot x_{M \check{z}}-k_{f} \cdot k_{p v} \cdot k_{p} \cdot x_{M}-\frac{k_{f} \cdot k_{p v}}{200} \cdot v_{M}
\end{aligned}
$$

and for state model reads:

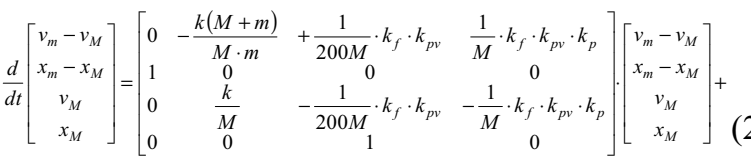

$$
\begin{aligned}
& +\left[\begin{array}{c}
-\frac{1}{M} \cdot k_{f} \cdot k_{p v} \cdot k_{p} \\
0 \\
\frac{1}{M} \cdot k_{f} \cdot k_{p v} \cdot k_{p} \\
0
\end{array}\right] \cdot x_{M z} \\
& c^{T}=\left[\begin{array}{llll}
0 & 0 & 0 & 1
\end{array}\right]
\end{aligned}
$$

If mass $\mathbf{m}$ is ,extended" to $\mathbf{1 m}$ in the positive direction and reference value $\mathrm{x}_{\mathrm{M}_{\bar{y}}}=0$, then after mass $\mathbf{m}$ releasing, the regulators in cascade will ensure almost mass M perfect still stand. Mass $\mathbf{m}$ after releasing practically oscillates undamped. Mentioned is on Fig.3.

For $\mathrm{M}=400 \mathrm{~kg} ; \mathrm{m}=1000 \mathrm{~kg} ; \mathrm{k}=2.10^{5} \mathrm{~N} / \mathrm{m}$; and $\mathrm{k}_{\mathrm{f}}=2.10^{6} \mathrm{~N} / 1 \mathrm{~V} ; \mathrm{k}_{\mathrm{p}}=3 ; \mathrm{k}_{\mathrm{pv}}=3$ we obtain system poles

$$
\begin{aligned}
& \mathrm{s}_{1}=-37.498+\mathrm{i} \cdot 209.99 \\
& \mathrm{~s}_{2}=-37.498-\mathrm{i} \cdot 209.99 \\
& \mathrm{~s}_{3}=-0.00183+\mathrm{i} \cdot 14.064 \\
& \mathrm{~s}_{4}=-0.00183-\mathrm{i} \cdot 14.064
\end{aligned}
$$

\section{Corresponding author: urednicek@fai.utb.,cz}




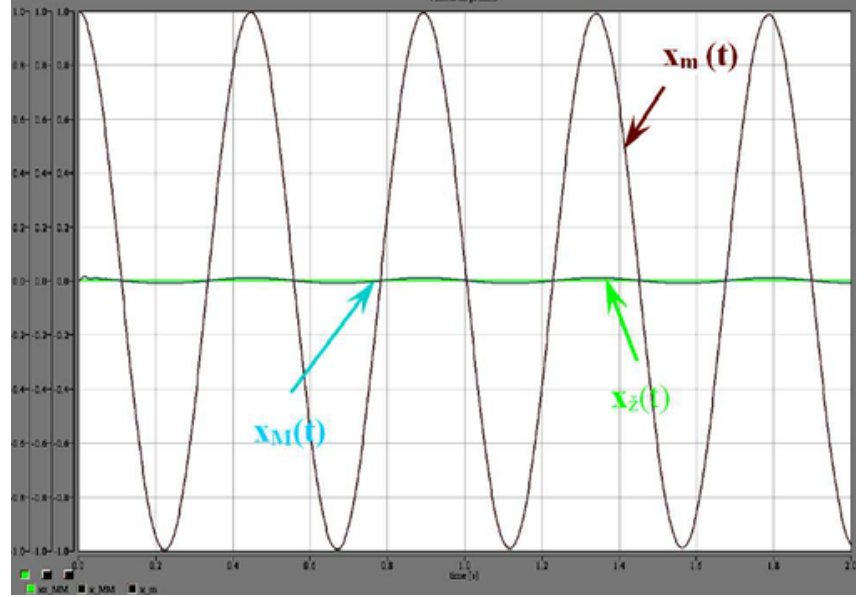

Fig. 3. The mass $\mathbf{m}$ undamped oscillation and masses $\mathbf{M}$ stabilization.

If we'll require obtaining from designed complete state regulator new required poles

$$
\begin{aligned}
& \mathrm{s}_{1}=-50 ; \mathrm{s}_{2}=-50 \\
& \mathrm{~s}_{3}=-15+\mathrm{i} \cdot 15, \\
& \mathrm{~s}_{4}=-15-\mathrm{i} \cdot 15
\end{aligned}
$$

then is possible to create this complete state regulator as

$$
\underline{\mathrm{r}}^{\mathrm{T}}=\left[\begin{array}{llll}
0.010444 & 0.008333 & 0.011667 & -0.875
\end{array}\right]
$$

(see Fig.4.)

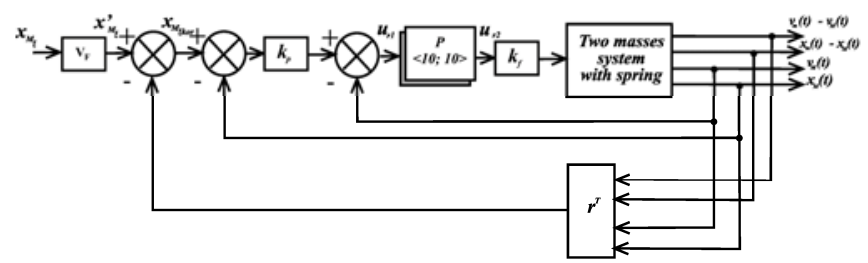

Fig. 4. Complete state regulator.

Control structure from Fig.4. will ensure the system behaviour for the same mass $\mathbf{m}$,,extending ", according to Fig.5.

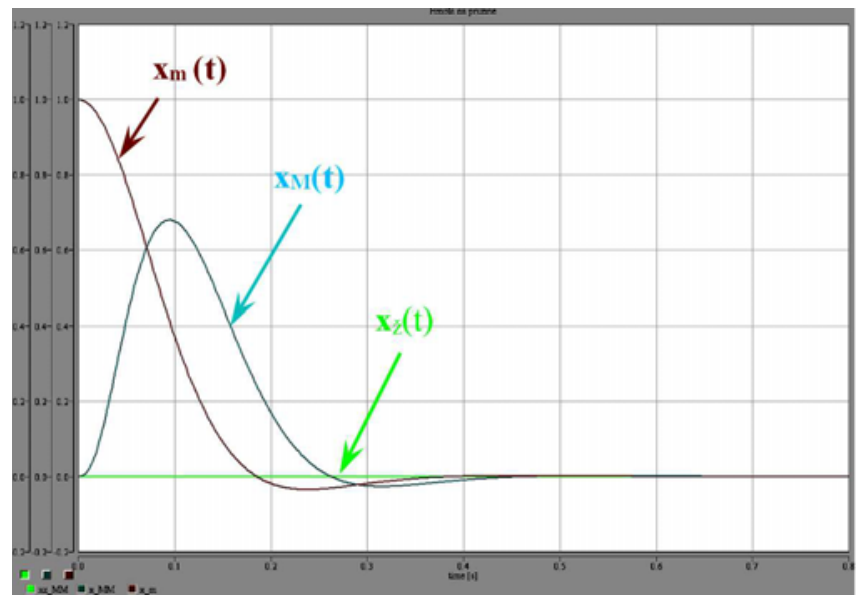

Fig. 5. Complete state regulator.

It is evident that controlled mass $\mathbf{M}$, suppresses mass m oscillations now.

Fig.6 shows such system response on mass $\mathbf{M}$ desired position jump $\mathbf{x}_{\mathbf{M z ̌}}=\mathbf{5} \mathbf{~ m}$.

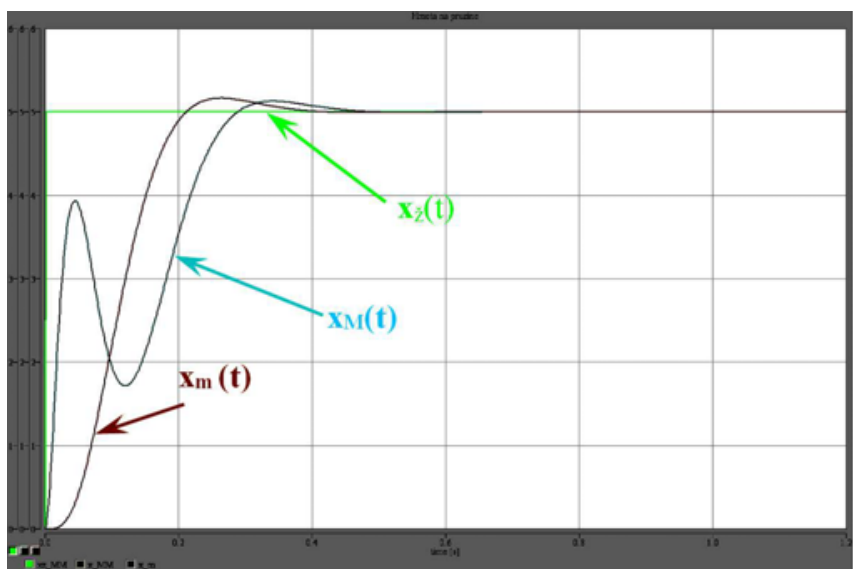

Fig. 6. Response on required $\mathbf{M}$ position jump with $\mathbf{m}$ and $\mathbf{M}$ masses oscillation active damping.

Measurement mass $\mathbf{m}$ position and speed (eventually $\mathrm{x}_{\mathrm{m}}-\mathrm{x}_{\mathrm{M}}$ and $\mathrm{v}_{\mathrm{m}}-\mathrm{v}_{\mathrm{M}}$ ) presents indeed problem in general.

If we design complete linear observer system with select observer matrix eigenvalues

$$
\begin{aligned}
& \mathrm{s}_{1}=-50+300 \cdot \mathrm{i} \\
& \mathrm{s}_{2}=-50-300 \cdot \mathrm{i} \\
& \mathrm{s}_{3}=-1+\mathrm{i} \cdot 15 \\
& \mathrm{~s}_{4}=-1-\mathrm{i} \cdot 15
\end{aligned}
$$

and we will use only part of reconstructed state quantities from it, then structure from Fig.7 will ensure identical system behaviour as we can see on Fig. 6 .

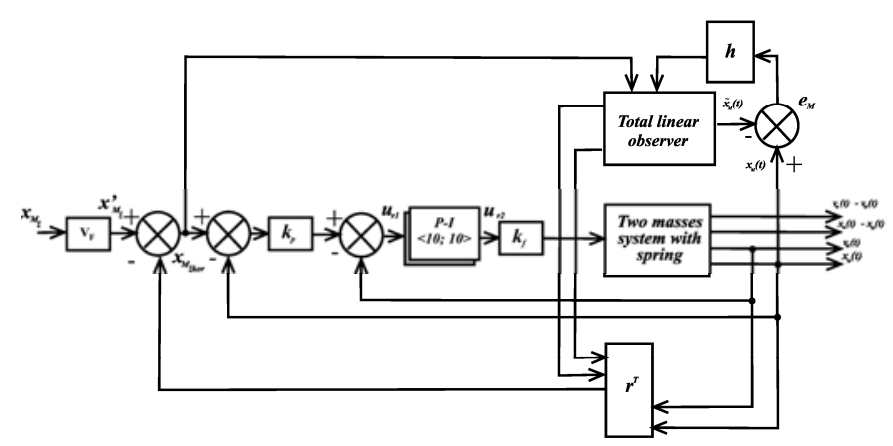

Fig. 7. Active damping with linear observer of $\mathbf{m}$ and $\mathbf{M}$ masses.

\section{Active damping of mass system with two degree of freedom}

Study ordering from Fig. 8. and Fig 9., so system with two degree of freedom (planar motion without friction, normal to gravitation direction), whereas external mass $\mathbf{M}$ is controlled by e.g. electrohydraulic translational positional servo system producing force $\mathbf{f}(\mathbf{t})$. This mass can move only in $\mathbf{x}$ axis direction. 


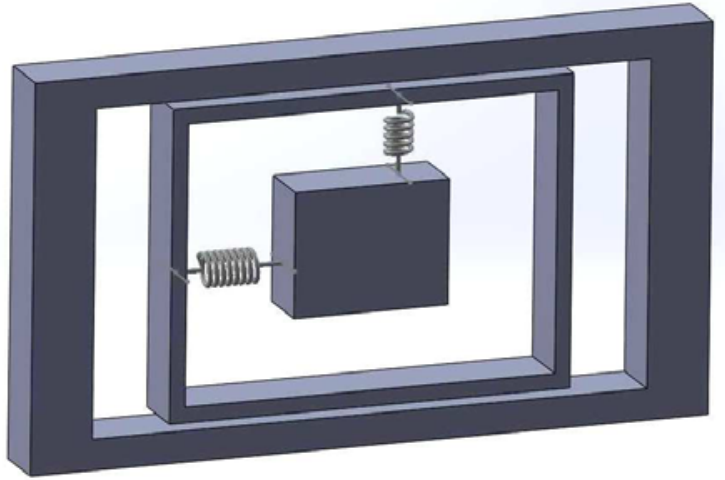

Fig. 8. Ordering of two masses system with two degree of freedom.

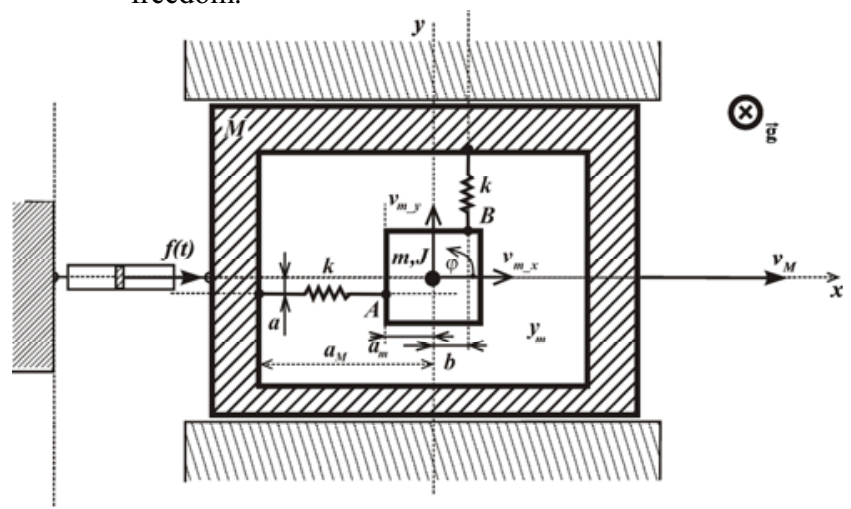

Fig. 9 Two masses system with two degree of freedom scheme.

Inside of this material „frame" is mass m, „hung" on two linear springs without dissipative damping, whose axes are, in quiescent state (mass $\mathbf{M}$ and $\mathbf{m}$ centres of gravity are in identical point, point $[0,0]$, angle $\varphi=0$ ) displaced in a parallel way from coordinates axes. Mass $\mathbf{m}$ positive rotation direction is counter-clockwise.

Create physical simulation model of given ordering by means of simulation system for multiport simulation physical models DYNAST ${ }^{* *}$

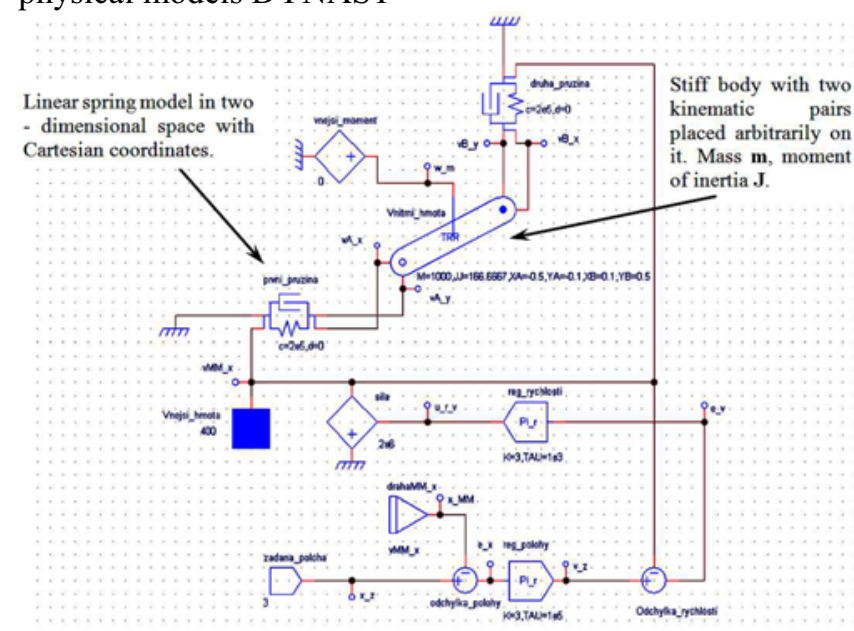

Fig. 10 Multiport physical model of system from Fig.9..

${ }^{* *}$ http://virtual.cvut.cz/dyn/examples/
Graphic model setting is on Fig. 10.

Fig.11. shows system undamped response on mass $\mathbf{M}$ rerquired position jump in time $\mathbf{t}=\mathbf{0 s} ; \mathbf{x}_{\mathbf{M z ̆}}=\mathbf{3 m}$.

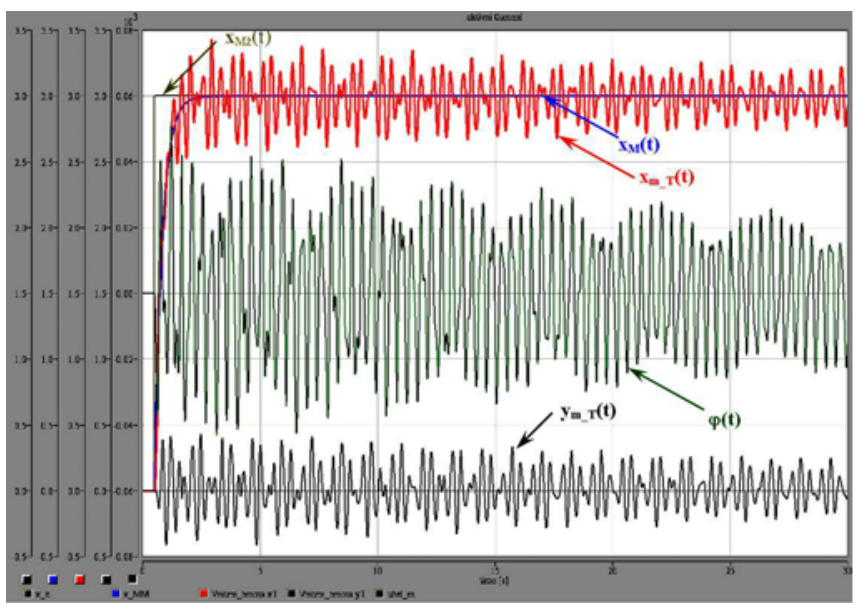

Fig. 11. Undamped system from Fig .9. and Fig.10. behaviour for desired $\mathbf{M}$ mass jump of position

It's seen that the outer $\mathbf{M}$ mass fast movement to required position produces not only mass $\mathbf{m}$ oscillations in $\mathbf{x}$ axis, but also in $\mathbf{y}$ axis. In addition, thanks to asymmetric springs bearing, at this mass $\mathbf{m}$ yawing oscillation happens and successively mechanical energy "flows" between both axes.

With regard of select ordering of both material bodies and their possible motion control way, use only $\mathbf{x}$ axis for active damping. Employ piece of knowledge from previous one-dimensional case. Design complete state regulator for control and active damping in $\mathbf{x}$ axis and subsequently propose linear observer for $x_{m}-x_{M}$ and $\mathrm{v}_{\mathrm{xm}}-\mathrm{v}_{\mathrm{xM}}$ reconstruction. It means we suppose that we are able to measure mass $\mathbf{M}$ position and speed in $\mathbf{x}$ axis and differences $x_{m}-x_{M}$ and $v_{x m}-v_{x M}$ we will obtain from observer.

Require the same mass $\mathbf{M}$ jump as in Fig. 11, but with above mentioned active dumping with state regulator and observer in $\mathbf{x}$ axis. On Fig. 12 is seen that system mechanical behaviour is damped. Not perfectly, because we dumped only part of energy.

\section{Conclusions}

Paper shows mechanical systems with two degree of freedom active damping simple possibility, applicable in case that the action interventions are available only in one axis. Designed one-dimensional complete state regulator is able, thanks ,energy overflow" of unsymmetrical embedded springs, to damp significantly also oscillations of mass, which it is impossible to influence directly by action quantities. 


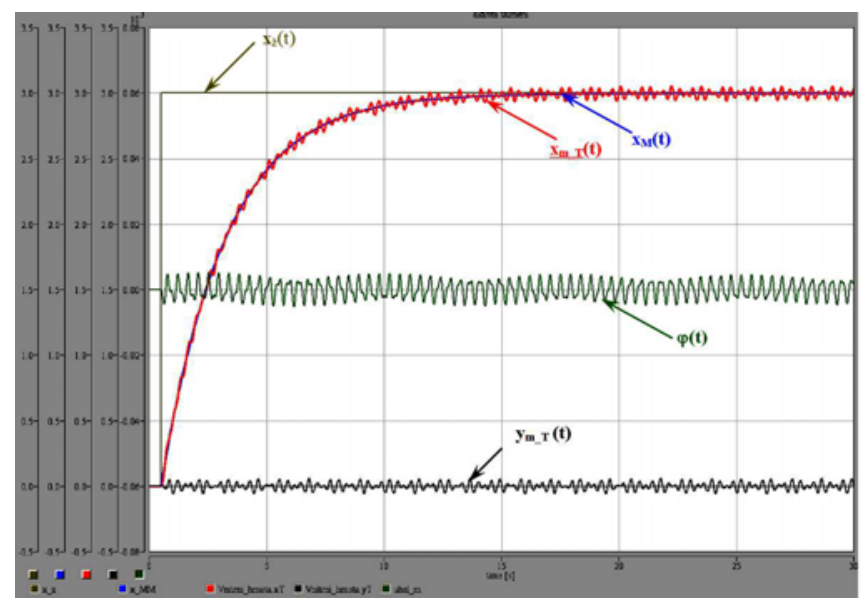

Fig.12. Behaviour of system from Fig .9. and Fig 10. damped in one axis at $\mathbf{M}$ position desired jump

Regarding to inner mass position and speed complicated measurability (respectively $\mathrm{x}_{\mathrm{m}}-\mathrm{x}_{\mathrm{M}}$ and $v_{x m}-v_{x M}$ ) for information about these quantities the linear observer was used.

In the event of two-dimensional model using, eventually with two-dimensional observer it is possible to achieve system complete active damping.

\section{References}

1. B. Friedland, B., McGraw-Hill, New York (1986)

2. L. Zboray, Edičné stredisko VŠT v Košiciach (1985) (In Slovak language)

3. Z. Úředníček, T. Bata university in Zlin (in Czech language), (2012)

4. H. A. Darweesh, M. Roushdy , H. M. Ebied, B.M. Elbagoury, Proceedings of the WSEAS International Conference Mathematical Applications in Science and Mechanics. (2013)

5. S. Hubalovsky, P. Kadlec, L. Mitrovic, P. Hanzalova, Proceedings of the 3rd International Conference on Mathematical Models for Engineering Science (MMES '12). Paris, France, (2012)

6. http://virtual.cvut.cz/dynast/ (23.2.2017)

7. Z. Úředníček, International journal of mechanics, 10, (2016)

8. Z. Úředníček, R. Drga, MATEC Web Conf. 76, (2016) 